\title{
Current scenario of rational usage of various drugs in indoor patients
}

\author{
Shaheen Saeed $^{\mathrm{a}, *}$, Parvez Saeed ${ }^{\mathrm{b}}$, Varun Sharma ${ }^{\mathrm{a}}$
}

${ }^{\mathrm{a}}$ Department of Pharmacology, GSVM Medical College, Kanpur, India,

${ }^{\mathrm{b}}$ Department of General Medicine, S. N. Medical College, Agra, India

Received: 25 July 2012

Revised: 28 July 2012

Accepted: 30 July 2012

*Correspondence to:

Dr. Shaheen Saeed,

Email: drssarosh@yahoo.com

\begin{abstract}
Background: Irrational prescribing of drugs is of common occurrence in clinical practice. Rational drug prescribing is defined as "the use of the least number of drugs to obtain the best possible effects in the shortest period and at a reasonable cost". The present study was designed to evaluate the practice of rational prescription in patients (cases) admitted in various wards of G.S.V.M. Medical College and associated hospitals at Kanpur.

Methods: This study was carried out on patients admitted in different wards. For the study of drug prescribing patterns, each prescribed drug was counted only once for a patient, irrespective of change in dose and route of administration. WHO guidelines were taken into consideration. Both distribution of type of drug as well as drug category were evaluated in different departments thereafter. The characteristics chosen on each prescription provided the incidence of poly pharmacy and frequencies of prescribing of individual drug were analyzed. The data obtained were subsequently categorized systematically and analyzed by taking WHO guidelines into consideration.

Results: The most commonly prescribed drugs were vitamins and tonics $(57.5 \%)$ followed by anti-microbial agents $(12.7 \%)$, non-steroidal antiinflammatory drugs $(10.5 \%)$, anti-hypertensive $(5.2 \%)$, anti cough remedies and acid peptic disease drugs. Generic drug prescription was very low as most of drugs prescribed were proprietary. A low number of Fixed Dose Combinations (FDCs) were prescribed, this finding was in accordance with the WHO recommended list of FDCs. Items on the WHO model list of essential drugs were prescribed frequently. The use of drugs has been found to be in accordance with the disease, the patient had.

Conclusions: Present study highlighted that there was a high incidence of irrational prescribing practice that increased with the total number of drugs per prescription.
\end{abstract}

Keywords: Fixed-dose-combinations (FDCs), Poly-pharmacy, Essential drugs

\section{INTRODUCTION}

Irrational prescribing of drugs is of common occurrence in clinical practice. ${ }^{1}$ Most common and important reasons being lack of knowledge about drugs, unethical drug promotions and moreover, irrational prescribing habits by the clinicians.

The prescription order is an important transaction between the doctor and the patient. ${ }^{2}$ The prescribing behaviour of the doctor depends upon the input from various sources like patients, academic literatures, professional colleagues, commercial publicity and government regulations. Various prescribing errors are result of ineffective use of these inputs and are very common in clinical practices. ${ }^{3}$

Surveillance of drug use by the doctors, within the institution as well as in the community is assuming an increasingly important role in therapeutics. Hence adequate prescribing information to the patient is imperative with drugs. ${ }^{4}$ Erratic usage of drugs by the physicians exposes their patients unduly to unjustifiable risk.

The continuous monitoring of prescriptions may help to identify the problems involved in therapeutic decisions and promote the rational prescribing. 5 


\section{METHODS}

Study Setting: This study was carried out in various wards of G.S.V.M. Medical College, Kanpur and associated hospitals of Kanpur for a period of 6 months. The patients admitted in different wards, undergoing medical management were followed up, and records were collected from following departments:

- General Medicine,

- Cardiology,

- Gastroenterology,

- Pulmonary Medicine,

- General Surgery,

- Ophthalmology,

- Otorhinolaryngology, and

- Obstetrics and Gynecology

Study Design: This study has been aimed to obtain data on the prescribing pattern of various drugs by the specialists and study those drug interactions which influence the efficacy and safety of human drug therapy. The patient and drug data were recorded on a proforma which included all the necessary information regarding patient, patient's illness, medications and follow up.

Selection of Indications: The following basic drug use indicators were used in the study. ${ }^{6}$

- $\quad$ Average number of drugs prescribed per patient;

- Percentage of drugs when an antibiotic was prescribed;

- $\quad$ Percentage of drugs when injections were prescribed;

- Percentage of drugs prescribed by generic name;

- Percentage of drugs prescribed from essential drug list;

- Percentage of fixed dose combinations versus single agents;

- Percentage of drugs when vitamins/ tonics were prescribed;

- Analysis of rationality of administration of AMA was done by modified Kunin Criteria. ${ }^{7}$
Evaluation of rationality: The categories designed by Kunin et al $^{7}$ was used with slight modifications to describe the judgment on rationality:

I: Agree with the use of therapy given as in the prescription. The treatment is appropriate in terms of choice of drug, dose, dosage regimen, duration of therapy.

II. Agree with the use of therapy but a potentially fatal infection cannot be ruled out.

III. Agree with the use of therapy but a different (usually less expensive and toxic) combination of therapy is preferred.

IV. Agree with the use of therapy but a modified dose, dosage regimen and duration would be recommended.

V. Disagree with the use of therapy, administration is unjustified or unnecessary use of drugs.

Category I \& II essentially indicate "Appropriate" therapy

Category III \& IV indicate that there is some major deficiency in the choice or use of drugs by the doctor managing the problem.

These indicators are highly standardized in terms of their definition and facilitate the quick and reliable assessment of drug use in health care. ${ }^{8}$

\section{CORE INDICATORS ${ }^{9}$}

\section{Prescribing Indicators:}

- Average number of drugs per patient was calculated by dividing the total number of different drug products prescribed by the number of patients surveyed.

- Percentage of different categories of drugs was also determined by dividing the number in that category by total number of drugs prescribed, multiplied by 100 .

- Percentage of antibiotic prescribed was determined by dividing the number of antibiotics prescribed by the total number of drugs prescribed, multiplied by 100 .

- The categories designed by "Kunin et al" were used with slight modification to assess the rational use of antibiotics.

- $\quad$ Percentage of encounters with an injection prescribed was calculated by dividing the number of patient encounters during which an antibiotics or an injection was prescribed by the total number of encounters surveyed, multiplied by 100 .

- $\quad$ Percentage of drugs prescribed by generic name was determined by number of drugs prescribed by generic 
name by the total number of drugs prescribed, multiplied by 100 .

- $\quad$ Percentage of drugs prescribed from Essential Drug List was determined by dividing the number of products prescribed from essential drug list of the hospital by the total number of drugs prescribed, multiplied by 100 .

- The ratio of fixed dose combinations to single agents was evaluated.

- Percentage of vitamins / tonics prescribed was determined by the number of vitamins / tonics prescribed by total number of drug prescribed, multiplied by 100 .
- $\quad$ Errors in medication prescribed were also reviewed.

The rational use of Fixed Dose Combinations (FDCs) per World Health Organization (WHO) guidelines was also evaluated using WHO essential drug list ${ }^{10}$ which includes only 25 drug combinations.

\section{RESULTS}

Table 1: shows total 548 cases were taken from various departments. The average drugs prescribed per patient was found to be 8.3 . The average was found to be highest (11.5) in the department of cardiology and lowest in the department of ophthalmology (5.5).

Table 1: Distribution of number of cases taken from various departments.

\begin{tabular}{|lllll|}
\hline $\begin{array}{l}\text { Name of } \\
\text { Departments }\end{array}$ & $\begin{array}{l}\text { No. of } \\
\text { cases }\end{array}$ & $\begin{array}{l}\text { Total no. of } \\
\text { drugs }\end{array}$ & $\begin{array}{l}\text { Average no. } \\
\text { of drugs }\end{array}$ & Range \\
$\begin{array}{l}\text { Ophaecology } \\
\text { Ophthalmology }\end{array}$ & 105 & 829 & 7.9 & $3-18$ \\
Otorhinolaryngology & 65 & 358 & 5.5 & $3-9$ \\
Cardiology & 60 & 461 & 7.7 & $4-16$ \\
Medicine (rest) & 70 & 806 & 11.5 & $5-21$ \\
Gastroenterology & 100 & 826 & 8.3 & $3-19$ \\
Respiratory Medicine & 95 & 856 & 9.0 & $3-18$ \\
Total & 50 & 415 & 8.3 & $6-12$ \\
\hline
\end{tabular}

Table 2: shows "antibiotic" usage was high in ophthalmology $(29.6 \%)$ and otorhinolaryngology cases $(30.4 \%)$ whereas it was found to be lowest in cardiology cases $(14.3 \%)$. Injectable prescribed were found to be high in cardiology $(30.4 \%)$, respiratory medicine $(28.9 \%)$ and other medicine cases $(43.6 \%)$.

Table 2: Distribution of percentage of encounters by type of drugs prescribed in various departments.

\begin{tabular}{|llllllll|}
\hline Type of Drugs & $\begin{array}{l}\text { Gynaeco } \\
\text { logy }\end{array}$ & $\begin{array}{l}\text { Ophthalmol } \\
\text { ogy }\end{array}$ & $\begin{array}{l}\text { Otorhinolar } \\
\text { yngology }\end{array}$ & $\begin{array}{l}\text { Cardiolo } \\
\text { gy }\end{array}$ & $\begin{array}{l}\text { Medici } \\
\text { ne }\end{array}$ & $\begin{array}{l}\text { Gastroent } \\
\text { erology }\end{array}$ & $\begin{array}{l}\text { Respiratory } \\
\text { Medicine }\end{array}$ \\
Antimicrobial & 19.4 & 29.6 & 30.4 & 14.3 & 19.4 & 16.4 & 15.7 \\
Injectables & 12.7 & 9.9 & 21.7 & 30.4 & 43.6 & 29.2 & 28.9 \\
Generic Drugs & 5.5 & 4.2 & 8.7 & 5.6 & 4.2 & 5.3 & 9.6 \\
Essential Drugs & 52.1 & 40.84 & 52.2 & 72.1 & 75.2 & 76.6 & 28.9 \\
FDC & 10.9 & - & 16.3 & 5.0 & 9.7 & 4.1 & 19.3 \\
Vitamins \& Tonics & 26.7 & 11.3 & 19.6 & 5.6 & 15.2 & 33.3 & 25.3 \\
\hline
\end{tabular}

Prescription of essential drugs was found to be high (76\%). Prescription of generic drugs was conspicuously low because most of the drugs prescribed were proprietary.

The percentage of encounter with FDCs was low because the vitamins and tonics were not included in this group, they were taken separately. Most of the vitamin and tonics were prescribed in gastroenterology (33.3\%) and gynecology (26.7\%). Least number of vitamins and tonics were prescribed in cardiology cases $(5.6 \%)$
Table 3: This table shows that AMA and vitamins and tonics are the most commonly prescribed drugs followed by non-steroidal anti-inflammatory drugs and acid peptic disease drugs. Percentage of antibiotics was highest in Ophthalmology and Otorhinolaryngology cases.

Table 4: (Analysis of case sheet for use of antibiotics) According to this table, this study shows anti-microbial agents were the most commonly prescribed drugs along with vitamins and tonics. Appropriate use of antimicrobial agents is seen in medicinal cases $(17.5 \%)$ and gastroenterology cases $(17.5 \%)$. In most of the cases, 
appropriate use was because of correct usage of antimicrobial in terms of dose, duration and dosage regimen. Inappropriate use was observed in otorhinolaryngology cases $(23 \%)$ as most anti-microbial agents prescribed were the FDCs. Investigations for bacteriological tests / smears / cultures and antibiotic sensitivity test were advised in only few cases.

Table 3: Distribution of percentage of encounters by category of drugs prescribed in various departments.

\begin{tabular}{|c|c|c|c|c|c|c|c|}
\hline $\begin{array}{l}\text { Category of } \\
\text { Drugs }\end{array}$ & $\begin{array}{l}\text { Gynaecolo } \\
\text { gy }\end{array}$ & $\begin{array}{l}\text { Ophthalm } \\
\text { ology }\end{array}$ & $\begin{array}{l}\text { Otorhinolar } \\
\text { yngology }\end{array}$ & $\begin{array}{l}\text { Cardiolo } \\
\text { gy }\end{array}$ & Medicine & $\begin{array}{l}\text { Gastroent } \\
\text { erology }\end{array}$ & $\begin{array}{l}\text { Respiratory } \\
\text { Medicine }\end{array}$ \\
\hline Antimicrobials & 19.39 & 29.58 & 30.44 & 14.29 & 19.39 & 16.37 & 15.66 \\
\hline NSAIDs & 12.73 & 21.13 & 19.57 & 11.18 & 12.12 & 10.53 & 7.23 \\
\hline $\begin{array}{l}\text { Vitamins \& } \\
\text { Tonics }\end{array}$ & 38.18 & 14.09 & 21.74 & 12.42 & 16.97 & 16.96 & 19.28 \\
\hline $\begin{array}{l}\text { Respiratory } \\
\text { Drugs }\end{array}$ & 2.42 & - & 8.70 & 4.35 & 6.67 & 9.36 & 28.92 \\
\hline $\begin{array}{l}\text { Acid peptic } \\
\text { Disease Drugs }\end{array}$ & 11.52 & 9.86 & 13.04 & 11.18 & 8.49 & 20.47 & 14.46 \\
\hline $\begin{array}{l}\text { Neurogenic } \\
\text { drugs }\end{array}$ & 2.42 & 5.63 & - & 5.59 & 16.97 & 4.68 & 2.41 \\
\hline CVS/Blood & 6.06 & 4.23 & 2.17 & 28.57 & 5.46 & 7.02 & 6.02 \\
\hline Anti diabetic & 3.03 & 2.82 & - & 6.83 & 7.88 & 5.26 & 2.41 \\
\hline Miscellaneous & 4.24 & 12.68 & 4.35 & 5.59 & 6.06 & 9.36 & 2.41 \\
\hline
\end{tabular}

In some cases, use of an antimicrobial was suddenly switched over to another antimicrobial after 1 or 2 days uses neglecting its duration make its inappropriate use. Total number of FDC formulations prescribed were 1340 including 770 for vitamins and tonics, 120 FDCs prescribed were recommended by $\mathrm{WHO}$ in its list of essential drugs. Other FDC formulations were found to be 450 only.

Table 4: Analysis of case sheet for use of antibiotics.

\begin{tabular}{|c|c|c|c|c|c|c|c|}
\hline $\begin{array}{l}\text { Category of } \\
\text { Consultation }\end{array}$ & $\begin{array}{l}\text { Gynaecolog } \\
\text { y }\end{array}$ & $\begin{array}{l}\text { Ophthalm } \\
\text { ology }\end{array}$ & $\begin{array}{l}\text { Otorhinol } \\
\text { aryngolog } \\
\text { y }\end{array}$ & $\begin{array}{l}\text { Cardiolog } \\
\mathbf{y}\end{array}$ & Medicine & $\begin{array}{l}\text { Gastroe } \\
\text { nterolog } \\
\mathbf{y}\end{array}$ & $\begin{array}{l}\text { Respirato } \\
\text { ry } \\
\text { Medicine }\end{array}$ \\
\hline Appropriate Use & & & & & & & \\
\hline I & 5 & 20 & - & & 10 & - & 20 \\
\hline II & 20 & 10 & 30 & - & 25 & 35 & 10 \\
\hline Subtotal & $25(12.5 \%$ & $30(15.0 \%)$ & $30(15.0 \%)$ & $15(7.5 \%)$ & $35(17.5 \%)$ & $35(17.5)$ & $30(15 \%)$ \\
\hline Inappropriate Use & & & & & & & \\
\hline III & 10 & 10 & 10 & 5 & 5 & 5 & 5 \\
\hline IV & 5 & 5 & 10 & 10 & 10 & 5 & 5 \\
\hline $\mathrm{V}$ & 5 & - & 5 & - & - & - & - \\
\hline Subtotal & $20(18.2 \%)$ & $15(13.6 \%)$ & $25(22.7 \%)$ & $15(13.6 \%)$ & $15(13.6 \%)$ & $10(9.1 \%)$ & $110(9.1 \%)$ \\
\hline
\end{tabular}

No FDCs (vitamin \& tonics excluded) have been prescribed in ophthalmology cases (Table 2).

\section{DISCUSSION}

Drug utilization studies commonly employ case history analysis with the average number of drugs per case as the most frequently used measure. Present study found an average of 8.3 drugs per case (Table 1).

The mean drug per prescription of hospitalized patients $(8.3 \%)$ was below the figure of 9.4 from United States of America and higher than those reported from Scotland (4.5), South Africa (4.3), Sweden (5.1) and Nepal (5.1). ${ }^{11}$ 
Prescription of more drugs increases the risk of drug interactions. $^{12}$

There was no case with single or 2 drugs prescribed (Table 2). Drugs are prescribed in a range of $3-21$. Average number of drugs prescribed was highest (11.5) in the department of Cardiology and lowest (5.5) in the department of Ophthalmology.

The issue of poly-pharmacy is of particular concern in older people who, compared to younger individuals, tend to have more disease conditions for which therapies are prescribed. It has been estimated that 20 percent of Medicare beneficiaries have five or more chronic conditions and 50 percent receive five or more medications. ${ }^{13}$ It is very obvious that cardiac diseases are commonly associated with older age and large numbers of co-morbidities (Diabetes Mellitus, Hypertension, Atherosclerosis, Obesity etc.), so it may be a reason behind highest average prescribed drugs in cardiac wards.

Antibiotics are one of the most commonly prescribed drugs. These drugs have also been reported as being misused $^{7}$. The inappropriate use of antibiotics leads to unwarranted side, adverse and toxic effects, problems of development of resistant bacteria, masking of signs of infection and have enormous financial impact. ${ }^{14}$ Investigations for bacteriological tests/ smears/ culture and antibiotic sensitivity tests were advised in $5.2 \%$ cases.

The use of vitamins and tonics was very high and irrational. The polypharmacy observed may be due to empirical use of AMAs (Anti-Microbial Agents) and vitamins and tonics. It was also observed that prescription of injectables also increased as the number of drugs per case increased.

Prescription of generic drugs was very low because most of the drugs prescribed by their proprietary names. It has been found in the study that only $8.96 \%$ of FDCs were in accordance with the WHO recommended list of FDCs. Items on the WHO model list ${ }^{14}$ of essential drugs were prescribed frequently (range $29-76 \%$ ). Use of essential drugs effect offers many advantages including cost, safety and effectiveness.

\section{CONCLUSIONS}

This study has highlighted that there was high incidence of irrational prescribing practices that increased with the total number of drugs per prescription. A large number of unnecessary combination formulations are prescribed for tonics, nutrition and enzymes. Irrational therapy needs to be identified and weeded out. The results of study call for interventional strategies to promote rational drug therapy.
1. Ramsay LE. Bridging the gap between clinical pharmacology and rational drug prescribing. $\mathrm{Br} \mathrm{J}$ Clin Pharmacol 1993; 35:575-6.

2. Benet LZ. Principles of prescription order writing and patients compliance instructions. In: Hardman JG, Limbird LE, Molinoff PB, Ruddon RW, Gilman AG editors. Goodman and Gilman's. The pharmacological Basis of Therapeutics. $9^{\text {th }}$ Ed. New York; mcgraw Hill 1996: 1617-706.

3. Kastury N, Singh S, Ansari KU. An audit of prescription for rational use of fixed dose drug combinations. India J Pharmacol 1999; 31:367-9.

4. Singh S, Ansari KU, Kastury N, Pandey RC. An audit of prescription for rational use of antibiotics. Indian J Pharmacol 1997; 18: 77-81.

5. Ansari KU, Singh S, Pandey RC. Evaluation of prescribing patterns of doctors for rational drug therapy. Indian J Pharmacol 1998; 30:43-6.

6. Kshirsagar MJ, Langade D, Patil S, Patki PS. Prescribing patterns among medical practitioners in Pune, India. Bulletin-World Health Org 1998; 76:271-5.

7. Kunin CM, Tupasi T, Craig WA. Use of antibiotics: A brief exposition of the problem and some tentative solutions. Ann Inter Med 1973; 79:555-60.

8. Hogerzeil HV et al. Field tests for rational drug use in twelve developing countries. Lancet 1993; 342:1408-10.

9. WHO. How to investigate drug use in health facilities: Selected drug use indicators Geneva. World Health Organization 1993 WHO/DAP 1993; $1: 1-87$.

10. WHO. $17^{\text {th }}$ WHO Model list of essential medicines: WHO Technical Report Series, No. 920. WHO2011.

11. Rehana HS, Nagarani MA, Rehan M. A study on the drug prescribing pattern and use of anti-microbial agents at a tertiary care teaching hospital in Eastern Nepal. Indian J Pharmacol 1998; 30:175-80.

12. Nies AS. Principles of therapeutics. In: Gilman AG, Roll TW, Taylor P, Nies AS. eds. Goodman and Gilman's, The pharmacological basis of therapeutics. $8^{\text {th }}$ ed. New York, NY: Mc Graw Hill $1992 ; 62-83$.

13. Tinetti ME, Bogardus ST Jr, Agostini JV. Potential pitfalls of disease specific guidelines for patients with multiple conditions. N Engl J Med 2004; 351:2870-4.

14. Nahata MC. Use of prophylactic antibiotics in cardiovascular thoracic surgery. Indian J Hosp Pharm 1987; 24:135-7.

\section{REFERENCES}

